\title{
DİŞSİZ REZORBE MANDİBULAYA FARKLI İMPLANTLARLA YAPILAN OVERDENTURE PROTEZLERDE GERİLME ANALİZİNİN DEĞERLENDİRİLMESİ: SONLU ELEMANLAR ANALİZi ÇALIŞMASI
} 4

\author{
STRESS EVALUATION OF OVERDENTURES SUPPORTED BY DIFFERENT IMPLANTS \\ IN EDENTULOUS RESORBED MANDIBLE: A FINITE ELEMENT ANALYSIS
}

\author{
Dr Öğr. Üyesi Gökçe SOĞANCI ÜNSAL* Doç.Dr. Güzin Neda HASANOĞLU ERBAŞAR ${ }^{* *}$
}

Makale Kodu/Article code: 4297
Makale Gönderilme tarihi: 03.02 .2020
Kabul Tarihi: 10.04 .2020

DOI : $10.17567 /$ ataunidfd. 718033
Gökçe Soğancı Ünsal: ORCID NO: 0000-0003-2017-5599

G. Neda Hasanoğlu Erbaşar: ORCID NO: 0000-0003-0743-199X

\section{Öz}

Amaç: Bu çalışmanın amacı rezorbe mandibular kretlerde greft uygulanarak ve uygulanmadan yerleştirilen farklı boyutlardaki implantlarla desteklenmiş overdenture protezlerin biyomekanik olarak değerlendirilmesidir.

Gereç ve Yöntem: Rezorbe mandibulayı taklit etmek amacıyla 2 tane 3 boyutlu mandibular model Tip II kemik özelliklerine göre oluşturuldu. $3.3 \times 11.5 \mathrm{~mm}$ (dar çaplı implant) ve $2.5 \times 13 \mathrm{~mm}$ (mini dental implant) boyutlarındaki osseointegre implantlar 3 boyutlu tarayıcı yardımıyla tarandı ve modellendi. İki adet dar çaplı implant kaninler bölgesine dik olacak şekilde yerleştirilerek Model 1 elde edildi. Dört adet mini dental implant ise ikisi lateral kesiciler bölgesine dik olarak diğer ikisi ise 1.premolar bölgesine $30^{\circ}$ açıyla yerleştirilerek Model 2 oluşturuldu. Her bir model için overdenture tasarlandı. Vertikal olarak $150 \mathrm{~N}$ oklüzal kuvvet tek (soldan) ve çift taraflı olacak şekilde protezin 1.molar dişi üzerinden uygulanarak veriler elde edildi.

Bulgular: İmplantlarda oluşan von Mises değerleri ve kortikal kemikte implant boynu etrafında meydana gelen asal gerilme sonuçları ve gerilme haritaları değerlendirildi. En yüksek von Mises değeri tek taraflı yüklemede Model 1'de yüklenen taraftaki implant çevresinde $33.64 \mathrm{MPa}$ olarak belirlendi. Kortikal kemikteki maksimum asal gerilme için en yüksek değer tek taraflı yüklemede Model 2'de sol lateral kesici bölgesindeki implant çevresinde 7.75 MPa olarak bulundu. Minimum asal gerilme değeri Model 1'de tek taraflı yüklemede soldaki implantın çevresinde 6.2 MPa olarak belirlendi.

Sonuç: Rezorbe dişsiz mandibular kretlerde greft uygulanarak yapılacak olan 2 dar çaplı implant destekli overdenture yerine greft uygulanmadan yapılacak 4 mini dental implant destekli overdenture seçeneği biyomekanik açıdan avantajılı olabilir. Bilateral dengeli oklüzyon oluşturulması da gelen kuvvet dağııımı açısından iyi bir seçenek olarak düşünülmektedir.

Anahtar Kelimeler: rezorbe mandibula, dental implant, greft, sonlu elemanlar analizi

\section{ABSTRACT}

Aim: The aim of this study was to compare the biomechanical behavior of overdentures retained with different implant dimensions with or without using graft in a resorbed mandible.

Material and Methods: To simulate the resorbed mandible two 3 dimensional models were created according to the Type II bone properties. $3.3 \times 11.5 \mathrm{~mm}$ (narrow diameter implant) and $2.5 \times 13 \mathrm{~mm}$ (mini dental implant) implants were scanned using 3 dimensional scanner and modelled. Model 1 was created as the two narrow diameter implants were placed vertically in the canine area, 4 mini dental implants were placed as two of them in lateral incisor area vertically and the rest two implants were placed in 1.premolar region with $30^{\circ}$ inclination to create Model 2. Overdentures were designed for each model. $150 \mathrm{~N}$ vertical occlusal force were applied from 1.molar tooth of overdenture, unilaterally and bilaterally and data were obtained.

Results: The von Mises stresses on implants and principal stresses on cortical bone around implant necks and stress patterns of models were evaluated. The highest value of von Mises stress was in the implant on the loaded side under unilateral loading in Model 1 as $33.64 \mathrm{MPa}$. Maximum principal stresses was the highest in Model 2 around cortical bone in left lateral incisor area under unilateral loading and found as 7.75 MPa. The highest value of minimum principal stress was determined 6.2 MPa around cortical bone in the left implant area under unilateral loading.

Conclusion: In a resorbed mandible 4 mini dental implant retained overdenture choice without using graft might be preferable instead of 2 narrow implant retained overdenture using graft procedure in terms of biomechanical aspect. Bilateral balanced occlusion might be better for distribution of occlusal forces.

Key Words: resorbed mandible, dental implant, graft, finite element analysis

*Ankara Yıldırım Beyazıt Üniversitesi Diş Hekimliği Fakültesi Protetik Diş Tedavisi A.D. Ankara.

**Ankara Yıldırım Beyazıt Üniversitesi Diș Hekimliği Fakültesi Ağız, Diș ve Çene Cerrahisi A.D. Ankara

Kaynakça Bilgisi: Soğancı Ünsal G, Hasanoğlu Erbaşar GN. Dişsiz Rezorbe Mandibulaya Farklı İmplantlarla Yapılan Overdenture Protezlerde Gerilme Analizinin Değerlendirilmesi: Sonlu Elemanlar Analizi Çalışması. Atatürk Üniv Diş Hek Fak Derg 2020; 30: 457-63.

Citation Information: Soganci Unsal G, Hasanoglu Erbasar GN. Stress Evaluation of Overdentures Supported by Different Implants in Edentulous Resorbed Mandible: A Finite Element Analysis. J Dent Fac Atatürk Uni 2020; 30: 457-63. 


\section{GİRİş}

Dişler kaybedildikten sonra alveolar kemiğin hem yüksekliğinde hem de genişliğinde meydana gelen kayıplar kaçınılmazdır. ${ }^{1}$ Dişsiz ve rezorbe mandibulaya yapılan protezlerin stabilite ve retansiyon için endoosseoz implantların kullanımı iyi bir tedavi alternatifidir ve implant destekli overdenture protezler hasta memnuniyeti açısından da oldukça başarılıdır. ${ }^{2-4}$ Anatomik yapılardan kaynaklanan sınırlamalar implant yerleşim bölgelerini etkileyebilmektedir. ${ }^{4}$ Alt çenelere yapılacak overdenture protezler için önerilen minimum implant sayısı ikidir.5,6 Genellikle bu iki implant için kanin bölgeleri tercih edilmektedir. Ancak bunun dışında alternatif olarak kemik miktarına bağlı olarak interforaminal bölgede lateral ve premolar bölgelerini de tercih etmek mümkündür. Hatta yerleşim yerine göre interforaminal bölgede gerilme analizi açısından lateral bölgenin daha avantajlı veya premolar bölgenin daha iyi sonuçlar gösterdiğine dair farklı sonuçlar mevcuttur. ${ }^{6}$

Yetersiz kemik varlığında hastalara çeşitli cerrahi prosedürler uygulanabilmektedir. Ancak bu prosedürler özellikle yaşı hastalar için kabul edilebilirliği zor ve hastaların genel sağlık durumunu da etkileyebilecek uzun süreli ve masraflı bir tedavi sürecine yol açmaktadır. ${ }^{2,3,7}$ Cerrahi prosedürler arasında alveoler kret split tekniği, sinirin lateralizasyonu, üst çenede sinüs ogmentasyonu yer almaktadır. ${ }^{1}$ Bunlar dışındaki cerrahi prosedürlerden biri de greft uygulamasıdır. Ancak implant stabilitesinin artmasında greftlerin katkısı tam olarak bilinememektedir. Biyomekanik açıdan ise greft konulan kemiklerde, gelen kuvvetlerin tolere edilmesi greft materyaline bağlı olarak değişmektedir. Zamanla marjinal bölgede oluşan kemik kaybı kaçınımaz olmakta ve implant stabilitesini ve yaşam süresini etkilemektedir. Greft, implant, üst yapı ve kemik kaybı implantın sağ kalımı açısından değerlendirilen kriterler arasındadır. ${ }^{8}$

Geleneksel implantların yerleşimi için kemik şekillendirmesine veya greft uygulamasına gereksinim duyulan ve kemik miktarı yetersiz olan çenelerde mini dental implantlar (MDI) daha az invaziv bir cerrahi ile avantaj sağlamaktadır. ${ }^{2,3,9}$ Özellikle bukko-lingual kemik mesafesi dar olan kretlerde greft uygulamasına gerek duyulmadan, tek aşamada yerleştirilen MDI iyileşme süresinin kısa olması açısından da avantaj sağlamaktadır. ${ }^{3,10,11}$ Eskiden MDI geleneksel implantların osseointegrasyon sürecinde kullanılmak üzere geçici restorasyonlar için uygulanmış olmasına karşın araştırmacıların MDI'ın osseointegre olabildiğini tespit etmesinden sonra daimi amaçlı olarak da kullanılmaya başlanmıştır.7,9 MDI'ın biyomekanik özellikleriyle ilgili olarak çeşitli çalışmalar bulunmaktadır. ${ }^{2,3,7}$

Sonlu elemanlar analiz yöntemi diş hekimliğinde oldukça sık kullanılan biyomekanik bir analizdir ve iyi yorumlandığı takdirde klinik uygulamalar için fikir verir. Aynı zamanda kemik yapı, implant ve protetik parçaların mekanik olarak çiğneme kuvvetleri altındaki etkisi ile ilgili bilgi verir.,6,12 Biyomekanik analizlerde implantların osseointegrasyon oranı ile ilgili çalışmalar yapılmış ve bu oranın klinikteki oranlara daha çok yaklaşabilmesi için $\% 100, \% 75, \% 50$ ve $\% 25$ osseointegrasyon değerleri ile çalışmalar yapılmıştır. ${ }^{13,14}$ Çalışmalarda kullanılan \%100 oseeointegrasyon gerçek klinik durumu yansıtmadığı genellikle \%75-90 arasında bir osseointegrasyon oranının klinik için daha gerçekçi olduğu düşünülmektedir. ${ }^{13}$

Çalışmamızın hipotezi greft uygulanarak yapılan 2 tane dar çaplı implant kullanımı yerine 4 tane MDI kullanımının kuvvet dağıımı açısından daha avantajlı olabileceği ve MDI'ların dar çaplı implantlara alternatif olabileceği yönündedir. Bu çalışmanın amacı ise, greft uygulanarak yerleştirilen dar çaplı implantlar ve greft uygulanmadan yerleştirilen MDI'lar ile desteklenen overdenture protez yapılan rezorbe ve ince kretlere sahip dişsiz mandibulada kortikal kemik ve implantlar üzerinde oluşan gerilmenin sonlu elemanlar analizi ile değerlendirilmesidir.

\section{GEREÇ VE YÖNTEM}

3 boyutlu (3B) dişsiz mandibular model tip II kemik özelliklerine göre tasarlandı. Kortikal kemik miktarı $1.5 \mathrm{~mm}$, mukoza kalınlığı ise $2 \mathrm{~mm}$ olarak belirlendi. Spongiyoz kemik, kortikal kemikten bilgisayar yazılımındaki (3D Doctor, Able Software Corp, Lexington, ABD) Boolean yöntemi ile azaltılarak oluşturuldu. Bu şekilde oluşturulan 3 boyutlu dişsiz mandibula modellerinden rezorbe mandibula modelleri elde edildi. Rezorbe mandibulayı oluştururken mukoza ve kemik kalınlığı sabit tutuldu. Kemiğin bukko-lingual kalınlığı interforaminal bölgede MDI'ın yerleşmesine izin verecek ancak dar çaplı implantların yerleşimi için yeterli olmayacak şekilde $4.3 \mathrm{~mm}$ olarak belirlendi.

2 adet $3.3 \times 11.5 \mathrm{~mm}$ dar çaplı implant (MIS Implant Technologies Ltd., Bar-Lev Industrial Park, Israil) ve 4 adet $2.5 \times 13 \mathrm{~mm}$ MDI (Intra- lock International Inc, Boca Raton, Florida, $A B D$ ) bir tarayıcı (Nextengine, NextEngine Inc., California, ABD) kullanılarak taranarak modellendi. Dar çaplı implantlar 
için topuz başlı tutucular ve üzerine o ring lastik parçalar, MDI için o-ring tutucular tarandı ve modellendi. 3B modellerin bilgileri evrensel bir format olan stl (standard triangle language) formatında kaydedildi ve 3B yazılıma (Rhinoceros, Robert McNeel \& Associates, Seattle, WA, ABD) aktarıldı. Bu yazılımda tüm parçaların birbirleriyle bağlantısı sağlandı. İmplantlar 3B modellere yerleştirildi ve tasarım şu şekilde oluşturuldu:

Model 1: 2 adet $(3.3 \times 11.5 \mathrm{~mm})$ dar çaplı implant rezorbe mandibulanın kanin dişleri bölgesine yerleştirildi. Greft $2 \mathrm{~mm}$ kalınlığında modellenerek bukkolingual olarak kanin dişlerinin bukkal bölgelerine yerleştirildi.

Model 2: 4 adet $(2.5 \times 13 \mathrm{~mm})$ MDI interforaminal bölgeye; 2 implant sağ ve sol lateral kesiciler bölgesine dik olarak, 2 implant sağ ve sol 1 . premolar bölgesine meziale doğru $30^{\circ}$ açıyla bikortikal olarak yerleştirildi. (Şekil 1)

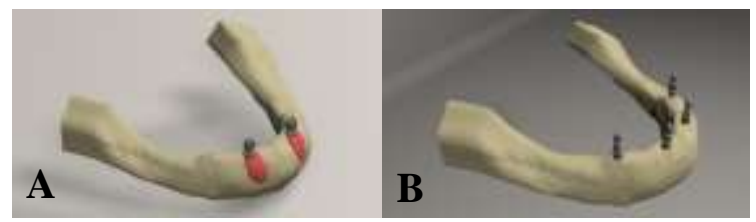

Şekil 1. (A) Model 1, (B) Model 2

Her bir model için overdenture protezler tasarlandı ve protetik tutucu parçalar birleştirildi. Materyal özellikleri literatürlere $3,8,13,15$ göre belirlendi ve Tablo 1'de gösterildi. Yapılan bazı sonlu elemanlar çalışmalarında ${ }^{13,15}$ belirtildiği üzere klinik durumu taklit etmek amacıyla kemik implant teması $75 \%$ olarak belirlendi. Tüm temas eden yüzeyler arasında sürtünme katsayısı 0.5 olarak belirlendi. ${ }^{2,16}$

Tablo 1. Materyal özellikleri

\begin{tabular}{|l|l|l|}
\hline & $\begin{array}{l}\text { Elastiklik Modülü (E) } \\
(\mathbf{M P a})\end{array}$ & $\begin{array}{l}\text { Poisson } \\
\text { Oranı (v) }\end{array}$ \\
\hline Greft & 11.0 & 0.3 \\
\hline Mukoza & 3 & 0.45 \\
\hline Protez & 3000 & 0.3 \\
\hline $\begin{array}{l}\text { Titanyum } \\
\text { (implant ve } \\
\text { abutment) }\end{array}$ & 110.0 & 0.35 \\
\hline Lastik (o-ring) & 5 & 0.4 \\
\hline
\end{tabular}

Modeller bir yazılım aracılığıyla (VRMesh Studio; VirtualGrid Inc, ABD) 10 düğüm noktalı tetrahedral elemanlar şeklinde ağ yapısına dönüştürüldü. Model 1 ve Model 2 için sırasıyla eleman sayıları 556,738 ve 289,366 , düğüm sayıları da 124,258 ve 68,263 olarak belirlendi. Ağ yapısı oluşturulan modeller katı modelleme için sonlu elemanlar analiz programına (Algor Fempro, Algor, Beta Drive Pittsburgh, PA, ABD) aktarıldı.

Mandibula belirli serbestlik seviyesinde alttan ve arka taraflardan sınırlandırılarak bağlı kabul edildi. Overdenture protezin 1.molar dişi üzerinden tek ve çift taraflı dikey olarak toplamda $150 \mathrm{~N}$ kuvvet uygulandı ve gerilme analizi yapıldı. ${ }^{6,7}$ (Şekil 2)

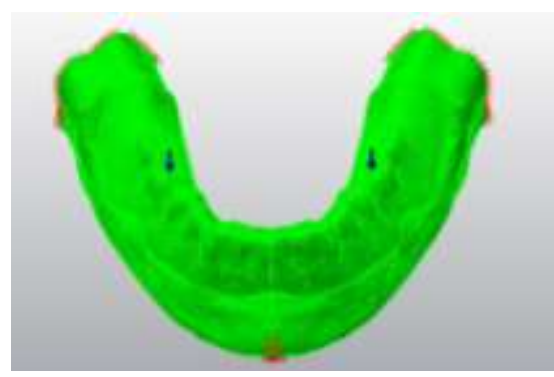

Şekil 2. Sınır koşulları ve uygulanan oklüzal kuvvet.

\section{BULGULAR}

Von Mises gerilmeler (maximum equivalents stress) kırılgan materyaller için bakılan gerilme değerleridir. Eğilebilen ve bükülebilen materyaller için ise maksimum ve minimum asal gerilmeler değerlendirilir. Maksimum asal gerilmeler çekme gerilmelerini temsil ederken minimum asal gerilmeler basma gerilmelerini temsil etmektedir. ${ }^{9,17}$ Bu çalışmada, implant boyun bölgesinde hem kortikal kemikte oluşan asal gerilmeler hem de implantlarda oluşan von Mises gerilmeler değerlendirildi. (Şekil 3) Gerilme haritasında maksimum asal gerilmeler kırmızı renkle minimum asal gerilmeler mavi renkle ifade edildi.

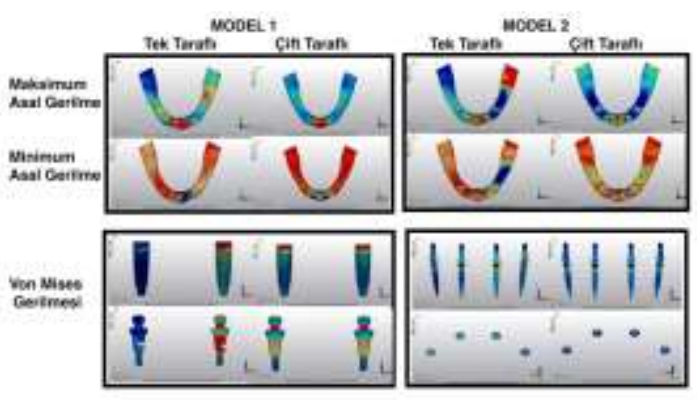

Şekil 3. Model 1 ve Model 2 için kemikte asal gerilmeler ve implant-protetik parçalarda von Mises gerilmeler. 
İmplant boyun bölgesi çevresindeki kortikal kemikte maximum ve minimum asal gerilmeler değerlendirildiğinde; Model 1'de tek taraflı yüklemede (soldan) kortikal kemikteki maksimum asal gerilme sol taraftaki implantın distalinde görülürken (1.87 MPa) çift taraflı yüklemede sağ implantın meziopalatinalinde (0.86 $\mathrm{MPa})$ görüldü. Minimum asal gerilmeler ise tek taraflı yüklemede soldaki implantın mezialinde (6.2 MPa) görülürken, çift taralı yüklemede sağ implantın meziobukkal tarafında (5.7 MPa) görüldü.

Model 2'de maksimum asal gerilme tek taraflı yüklemede (soldan) yüklenen taraftaki lateral kesici bölgesindeki implantın distalinde (7.75 MPa) gözlenirken çift taraflı yüklemede sol taraftaki lateral kesici bölgesindeki implantın distalinde (5.62 $\mathrm{MPa}$ ) görüldü. Minimum asal gerilmeler ise tek taraflı yüklemede yüklenen taraftaki 1.premolar bölgesindeki implantın mezialinde (3.53 MPa) gözlenirken çift taraflı yüklemede sağ tarafta lateral bölgesindeki implantın mezialinde (4.01 MPa) görüldü. Modellere göre maksimum ve minimum asal gerilme değerleri Grafik 1'de gösterilmiştir.

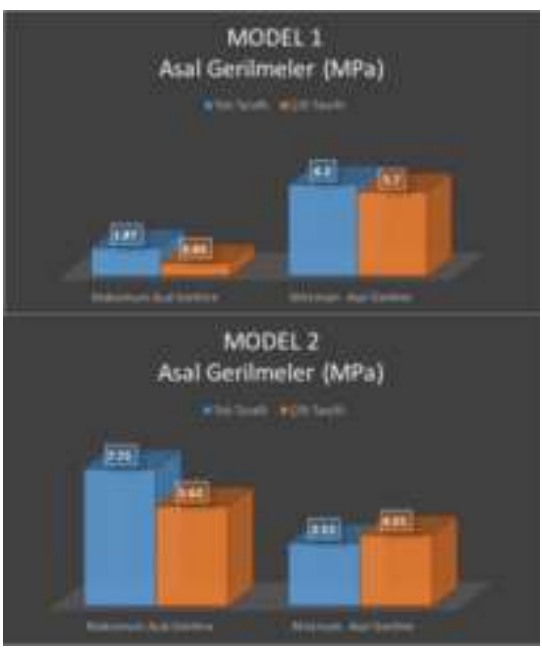

Grafik 1. Model 1 ve Model 2 için kortikal kemikte görülen maksimum ve minimum asal gerilme değerleri

İmplant ve protetik komponentlerde ise von Mises gerilme değerleri kıyaslandı. Buna göre gerilmelerin Model 1'de dar çaplı implantlarda tek taraflı yüklemelerde yüklenen taraftaki implantın boyun bölgesinde (33.64 MPa) yoğunlaştığı, abutmentlerin topuz başlarının boyun kısımları ve implant-abutment birleşim alanında yoğun olduğu görüldü. Çift taraflı yüklemede dar çaplı implantların boyun bölgelerinde (16.7 ve $16.6 \mathrm{MPa}$ ) ve topuz tutucuların boyun bölgesinde yoğunlaştığı görüldü. Tek taraflı yüklemeye göre çift taraflı yüklemede implant abutment birleşim bölgesindeki gerilmenin daha fazla olduğu tespit edildi.

Model 2'de MDI'larda gerilmelerin tek taraflı yüklemede; yüklenen tarafta premolar bölgesindeki implantın abutmentle birleştiği boyun bölgesinde yoğunlaştığı (21.23 MPa), çift taraflı yükle- mede; sol taraftaki premolar bölgesindeki implantın boyun bölgesinde $11.36 \mathrm{MPa}$ olduğu görüldü. Von Mises gerilme değerleri modellere göre Grafik 2'de gösterilmiştir.

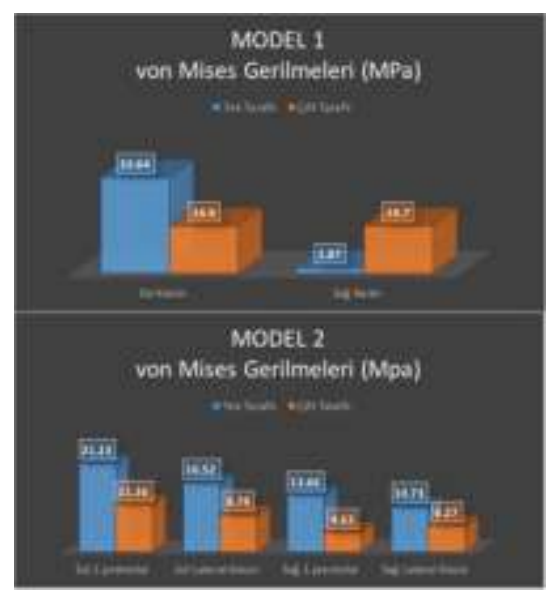

Grafik 2. Model 1 ve Model 2'de implantlarda görülen von Mises gerilme değerleri

\section{TARTIŞMA}

Çalışmanın hipotezi kabul edilmiştir. Tam dişsiz rezorbe mandibular kretlerde overdenture protezler için tasarlanan 2 planlama seçeneğinden, greft kullanılmadan yapılan 4 MDI destekli overdenture protez seçeneğinin, greft uygulanarak yerleştirilen 2 tane dar çaplı implantla desteklenen overdenture protez seçeneğine göre biyomekanik açıdan avantajlı olabileceği düşünüldü.

MDI ekonomik olması, cerrahi komplikasyonlarının daha az olması, post operatif sürecin daha iyi olması ve bukkolingual kemik miktarının yetersiz olduğu tam dişsiz vakalarda greft uygulamadan implant yapılmasına izin vermesi açısından avantajıdır. ${ }^{2}$

Chang ve arkadaşlarının ${ }^{2}$ yaptığı çalışmada, alt çene tam dişsizlik vakasında interforaminal bölgeye $3.5 \times 13 \mathrm{~mm}$ boyutunda 2 implant ve $1.8 \times 13 \mathrm{~mm}$ boyutlarında 4 MDI yerleştirilip gerilim analizi değerlendirilmiştir. Overdenture protez üzerinden yapılan yüklemede MDI'ın etrafında oluşan gerilim değerlerinin diğer 2 implanta oranla daha yüksek bulunduğu tespit edilmiştir. Ancak prematür temasların protez üzerinden 
kaldırılmasının ve bilateral dengeli oklüzyonun sağlanmasının kemikteki gerilim değerlerini azalttığı da bildirilmiştir. Bizim yaptı̆ı̆ı ı sonlu elemanlar çalışmasında bunun aksine; MDI'lar, dar çaplı implantlara oranla daha az gerilme dağılımı sergilemiştir. Nedeninin ise bizim çalışmamızdaki MDI'ların Chang ve arkadaşlarının ${ }^{2}$ kullandığı MDI'lardan daha kalın olması ve bikortikal fiksasyonla kemiğe yerleştirilmesi düşünülebilir. Bu çalışmanın sonuçları da bilateral yüklemede tek taraflı yüklemeye göre daha avantajlı bulunduğu için bilateral dengeli oklüzyonun sağlanmasının avantajı olması açısından iki çalışma benzerlik göstermektedir.

Rezorbe kretlerde iki implantın dik olarak konumlandırıı distaldeki implantların açılı olarak yerleştirilmesiyle oluşan konsept oldukça yaygınlaş mışır ve gerilme dağııııın azaltmaktadır. ${ }^{1}$ Moreira de Melo \& Francischone ${ }^{18}$ tarafından yapılan çalışmada bu konseptle $30^{\circ}$ açılya yerleştirdikleri $3.5 \times 11.5 \mathrm{~mm}$ ve $2.9 \times 11.5 \mathrm{~mm}$ boyutlarındaki implantlarla desteklenmiş overdenture protezlerde sonlu elemanlar analizi yapılmış ve sonuç olarak $3.5 \mathrm{~mm}$ çaplı implantlarda 2.9 $\mathrm{mm}$ çaplılara göre gerilme değerlerinin daha yüksek olduğu tespit edilmiştir. Bu sonuçlar bizim çalışmamızın sonuçları ile benzerlik göstermektedir.

MDI ilk olarak tek parça halinde piyasaya sunulmuştur ancak sonradan 2 parça halinde olan tipleri de çıkmışır. Bunların avantajı paralelliğin kolayca sağlanabilmesidir. Tek parça olanlarda ise rehber plak yardımıyla paralellik sağlanabilir. ${ }^{19}$ Çalışmamızda kullanılan MDI'ların tek parça olması klinikte kullanımı için rehber plaklara ihtiyaç duyulabilmesi açıından çalışmanın kısıtllıklarından biridir.

Inglam ve arkadaşları ${ }^{8}$ yaptıkları sonlu elemanlar gerilme analizi ile üst çenede farklı sertliklerdeki kemik greftleri ile kemik yıkımını değerlendirmişler ve yumuşak greft materyaline kıyasla sert greft materyalinin kullanıldığı durumlarda kemik rezorpsiyonunun daha az olduğunu ve implant prognozunun daha iyi olduğunu bildirmişlerdir. Ancak bu durumun aksine bizim çalışmamızda da sert greft kullanıımasına rağmen gerilmenin daha çok greftin olduğu bukkal bölgede yoğunlaştığı görülmüştür. Bu farkllığın bizim çalışmamızda tek greft materyalinin kullanımasından ve bu greft materyalinin mandibular kemikle kıyaslamasının yapılmış olmasından kaynaklandığı düşünülmektedir.

Topkaya \& Solmaz ${ }^{20}$ tarafindan yapılan sonlu elemanlar gerilme analizi çalışmasında mandibulada interforaminal bölgeye kaninler, lateraller, 1.premolar ve 2.premolar bölgelerine yerleştirilen 2 ve 4 geleneksel implant kombinasyonlu o-ring tutuculu overdenture planlamalarından en iyi gerilme dağııııının 2 implanta göre 4 implantın kullanıldığı modellerde kaydedildıği ve iki implantlı kombinasyonlarda ise 1.premolar bölgesine yerleştirilen modellerde olduğu tespit edilmiştir. Bunun aksine Hong ve arkadaşlarının ${ }^{21}$ yaptığı bir çalş̧mada ise rezorbe mandibulaya lateral, kanin ve premolar bölgelere 2 implant yerleştirilmiş ve topuz başlı tutucularla overdenture protezlerin yapıldığı planlamalar biyomekanik açıdan karşılaştııımış, sonuç olarak da lateral bölgeye yerleştirilen implantlarda gerilmelerin az ve stabilitenin daha iyi olduğu gözlenmiştir. Bizim çalışmamızda da Hong ve arkadaşlarının $^{21}$ çalışmasına benzer şekilde lateral implantta daha az gerilme kaydedilmiştir. Ayrıca Topkaya ve arkadaşlarının ${ }^{20}$ çalışmasına benzer şekilde de 4 implantı modellerin 2 implantı modellere göre gerilme dağıımı açısından daha avantajı olabileceği tespit edilmiştir.

Alvarez-Arenal ve arkadaşlarının ${ }^{6}$ interforaminal bölgede farklı diş bölgelerine yerleştirdikleri implantların gerilme analizinin değerlendirildiği çalışmalarında kanin bölgelerine yerleştirdikleri 2 implantlı planlamada bizim çalışmamızdakine benzer gerilme değerleri görülmüştür.

Çalışmanın sonuçları kendi içinde kıyaslandığında diğer çalışmalarda ${ }^{6,22}$ olduğu gibi tüm modellerde gerilmelerin implantın boyun bölgesinde ve bu bölgeye denk gelen kortikal kemik bölgesinde yoğunlaştığı görüldü. Her iki modelde de elde edilen von Mises gerilme değerleri titanyum alaşımının yorulma direnç değerlerinden $(840-1100 \mathrm{MPa})^{2,23,24}$ oldukça düşük olduğu için implant veya protetik komponentlerin kırılma riskinin yok denecek kadar az olabileceği düşünüldü. Ayrıca kemiğin çekme gerilmesi $100-121^{22,24} \mathrm{MPa}$ ve sıkışma gerilmesi de $167-173 \mathrm{MPa}^{23,25}$ olduğundan bu çalışmadaki sonuçlar kemiğin direnç seviyelerinin çok altında bulundu. Bu sonuca her iki model için kullanılan o-ring lastiklerin de etkisinin olduğu ve lastiklerin gelen kuvvetleri absorbe ederek implantlar ile çevre kemikte gerilme dağıımını olumlu yönde etkilediği düşünülmektedir.

Dört MDI implant destekli overdenture modelinde (Model 2) gerilme haritası incelendiğinde tek taraflı yüklemede sol taraftaki premolar bölge ile lateraller arası bölgede kortikal kemikte yoğun gerilme alanları tespit edildi. Sol tarafta gerilme değerlerinin yoğun görülmesinin implantların yüklemeye yakın bölgede olmasından ve protezin yüklenen tarafa doğru 
hareke- tinden kaynaklanabileceği düşünüldü. Aynı modelde çift taraflı yüklemede gerilmelerin lateraller arası böl- geye dengeli olarak dağıldığı tespit edildi. Tek taraflı yüklemeye göre çift taraflı yüklemede gerilmenin en distaldeki implant çevresinden laterale doğru kaymasının sebebi olarak protez stabilitesinin daha iyi sağlan- dığı ve kuvvetin dengeli bir şekilde dağılmasıyla geril- menin distaldeki implantların arkasında kalan geniş dişsiz alanlar tarafından absorbe edildiği düşünüldü. Ancak gerilmenin lateraller arasındaki dişsiz alanda yoğunlaşmasının bu bölgede dişsiz alanın daha kısa olması ve protezin daha çok implantlar üzerinde asılı gibi davranmasından olabileceği varsayıldı. Bu bölgede mukozanın gerilme absorbe edici etkisinden fazla yararlanılamadığı için lateraller arası ve lateral premolar arası bölgede gerilme dağılımlarının görüldüğü düşünüldü.

İki dar çaplı implant destekli overdenture modelinde (Model 1) ise tek taraflı yüklemede gerilmeler yüklenen taraftaki implant etrafında ve anterior bölgede yoğunlaşırken çift taraflı yüklemede implantlar arasında ve anteriordaki greft bölgesinde yoğunlaşmıştır. Bunun sebebi olarak posteriorda mukozanın gelen kuvveti tolere etmesi ve dişsiz kret üzerine dağıtması, kaninler arası bölgede ise protezin implantlar arasında mukozadan çok destek alamaması ve asılı kalması dolayısıyla implant ve implant arası bölgede daha çok gerilme oluşturması düşünülebilir. Böyle bir durumda anterior bölgeye uygulanan greft materyali üzerinde yoğunlaşan gerilmeler ilerleyen zamanlarda rezorpsiyona ve implant kaybına sebep olabileceği ön görülmektedir. Farklı greft materyallerinin denemesi ve gerilme analizlerinde kullanılmasının sonuçları etkileyip etkilemeyeceği başka bir araştırmada incelenebilir.

Model 1 ve Model 2 hem gerilme değerleri hem de gerilme haritaları değerlendirildiğinde Model 2'nin Model 1'e göre daha avantajlı olduğu görülmüştür. Bu durumda gerilme analizi açısından implant sayısının ve boylarının uzunluğunun implant çapından daha etkili olduğu düşünülebilir. Bu sonuçlar statik kuvvetler uygulanarak elde edildiğinden daha ileri değerlendirmelerinin yapılabilmesi için yorulma testlerinin de değerlendirilmesi gerekebilir.

\section{SONUÇ}

Çalışmadan çıkarılabilecek sonuçlar şöyle sıralanabilir:

1. Greft uygulanarak yerleştirilen 2 dar çaplı implant destekli overdenture seçeneğinden ziyade 4 tane mini dental implantlı overdenture tasarımının biyomekanik açıdan daha avantajlı olduğu söylenebilir.

2. Her iki modelde de vertikal kuvvetlerde implantlarda oluşan von Mises ve kortikal kemikte oluşan asal gerilme değerleri tolere edilebilir sınırlar dahilindedir.

3. Bilateral dengeli oklüzyon, gerilme dağılımları açısından 2 ve 4 implantlı overdenture planlamalarında kullanılması avantajlı bir oklüzyon türü olarak değerlendirilebilir.

\section{NOT: Maddi destek ve çıar iliskisi:}

Çalışmayı maddi olarak destekleyen kişi/kurulus yoktur ve yazarların çıkara dayalı bir ilişkisi yoktur.

\section{KAYNAKLAR}

1. Kilic E, Doganay O. Evaluation Of Stress In Tilted Implant Concept With Variable Diameters In The Atrophic Mandible: 3D Finite Element Analysis. J Oral Implantol. 2019. doi: 10.1563/aaid-joi-D-1900066. [Epub ahead of print]

2. Chang $\mathrm{SH}$, Huang $\mathrm{SR}$, Huang $\mathrm{SF}$, Lin $\mathrm{CL}$. Mechanical response comparison in an implant overdenture retained by ball attachments on conventional regular and mini dental implants: a finite element analysis. Comput Methods Biomech Biomed Engin. 2016;19:911-21.

3. Solberg K, Heinemann F, Pellikaan P, Keilig L, Stark H, Bourauel C, Hasan I. Finite element analysis of different loading conditions for implantsupported overdentures supported by conventional or mini implants. Comput Methods Biomech Biomed Engin. 2017;20:770-82.

4. Özdemir Doğan D, Polat NT, Polat S, Şeker E, Gül EB. Evaluation of "all-on-four" concept and alternative designs with 3D finite element analysis method. Clin Implant Dent Relat Res. 2014;16:501-10.

5. Meijer HJ, Raghoebar GM, Batenburg RH, Vissink A. Mandibular overdentures supported by two Brånemark, IMZ or ITI implants: a ten-year prospective randomized study. J Clin Periodontol. 2009;36:799-806.

6. Alvarez-Arenal A, Gonzalez-Gonzalez I, deLlanosLanchares $\mathrm{H}$, Brizuela-Velasco A, Martin-Fernandez $\mathrm{E}$, Ellacuria-Echebarria J. Influence of Implant Positions and Occlusal Forces on Peri-Implant Bone Stress in Mandibular Two-Implant Overdentures: A 3-Dimensional Finite Element Analysis. J Oral Implantol. 2017;43:419-28. 
7. Toth A, Hasan I, Bourauel C, Mundt T, Biffar R, Heinemann $F$. The influence of implant body and thread design of mini dental implants on the loading of surrounding bone: a finite element analysis. Biomed Tech (Berl). 2017;62:393-405.

8. Inglam $S$, Suebnukarn $S$, Tharanon W, Apatananon $\mathrm{T}$, Sitthiseripratip $\mathrm{K}$. Influence of graft quality and marginal bone loss on implants placed in maxillary grafted sinus: a finite element study. Med Biol Eng Comput. 2010;48:681-89.

9. Soğancı G, Yazıcıoğlu H. Evaluation of Stress Distribution of Mini Dental Implant-Supported Overdentures in Complete Cleft Palate Models: A Three-Dimensional Finite Element Analysis Study. Cleft Palate Craniofac J. 2016;53:73-83.

10. Griffitts TM, Collins CP, Collins PC. Mini dental implants: an adjunct for retention, stability, and comfort for the edentulous patient. Oral Surg Oral Med Oral Pathol Oral Radiol Endod 2005;100: 814.

11. Mundt T, Schwahn C, Stark T, Bi ar R. Clinical response of edentulous people treated with mini dental implants in nine dental practices. Gerodontology. 2015;32:179-87.

12. Aksan $M E$, Atsü $S$, Bulut $A C$. İmplant-protez bağlantısında sonlu elemanlar yöntemi . Atatürk Üniv Diş Hek Fak Derg 2018;28:91-7.

13. Mosavar A, Ziaei A, Kadkhodaei M. The effect of implant thread design on stress distribution in anisotropic bone with different osseointegration conditions: a finite element analysis. Int J Oral Maxillofac Implants. 2015;30:1317-26.

14. Lian Z, Guan H, Ivanovski S, Loo YC, Johnson NW, Zhang $H$. Effect of bone to implant contact percentage on bone remodelling surrounding a dental implant. Int $\mathrm{J}$ Oral Maxillofac Surg. 2010;39:690-98.

15. Dos Santos MBF, Meloto GO, Bacchi A, CorrerSobrinho L. Stress distribution in cylindrical and conical implants under rotational micromovement with different boundary conditions and bone properties: 3-D FEA. Comput Methods Biomech Biomed Engin. 2017;20:893-900.

16. Lin CL, Lin $\mathrm{YH}$, Chang SH. Multi-factorial analysis of variables influencing the bone loss of an implant placed in the maxilla: prediction using FEA and SED bone remodeling algorithm. J Biomech. 2010;43:644-51.

17. Gümrükçü Z , Kurt $S$. Atatürk Üniv Diş Hek Fak Derg 2019;29:534-41.
18. Moreira de Melo EJ, Francischone CE. Threedimensional finite element analysis of two angled narrow-diameter implant designs for an all-on-4 prosthesis. J Prosthet Dent. 2019. doi: 10.1016/j.prosdent.2019.09.015. [Epub ahead of print]

19. Damarisy A, Badr AMI, Rizk FN, Mohamed JF. Effect of one piece versus two piece mini implants on bone height of implant retained mandibular overdenture. OHDM 2017;16:1-6.

20. Topkaya T, Solmaz MY. The effect of implant number and position on the stress behavior of mandibular implant retained overdentures: A three-dimensional finite element analysis. J Biomech. 2015;48:2102-09.

21. Hong HR, Pae A, Kim Y, Paek J, Kim HS, Kwon KR. Effect of implant position, angulation, and attachment height on peri-implant bone stress associated with mandibular two-implant overdentures: a finite element analysis. Int J Oral Maxillofac Implants. 2012;27:69-76.

22. Georgiopoulos B, Kalioras K, Provatidis C, Manda $M$, Koidis $P$. The effects of implant length and diameter prior to and after osseointegration: a 2-D finite element analysis. J Oral Implantol. 2007;33:243-56.

23. Akça K, Iplikçioğlu H. Finite element stress analysis of the effect of short implant usage in place of cantilever extensions in mandibular posterior edentulism. J Oral Rehabil. 2002;29:350-56.

24. Kaleli N, Sarac D, Külünk S, Öztürk Ö. Effect of different restorative crown and customized abutment materials on stress distribution in single implants and peripheral bone: A three-dimensional finite element analysis study. J Prosthet Dent. 2018;119:437-45.

25. CaglarA, BalBT, AydınC, YılmazH, OzkanS. Evaluationofstress occuring on three different zirconia dental implants: three dimensional finite element analysis. Int J Oral Maxillofac Implants. 2010;25:95-103.

\author{
Yazışma Adresi \\ Dr.Öğr.Üyesi Gökçe Soğancı Ünsal \\ Ankara Yıldırım Beyazıt Üniversitesi \\ Diş Hekimliği Fakültesi \\ Protetik Diş Tedavisi A.D. \\ Etlik, Ankara, Türkiye. \\ Tel: 05326420486 \\ E Posta: dt.gokce@hotmail.com
}

